\title{
Fontes não-convencionais de proteína na primeira alimentação do bagre sul americano (Rhamdia quelen)
}

\author{
Unconventional protein sources in the first feeding of South American catfish \\ (Rhamdia quelen)
}

\author{
David Roque Hernández ${ }^{{ }^{*}}$ Sebastián Sánchez ${ }^{\mathrm{I}}$ Juan José Santinón ${ }^{\mathrm{I}}$ \\ Hugo Alberto Domitrovic ${ }^{I}$
}

\section{RESUMO}

O presente estudo teve como objetivo avaliar diferentes fontes de proteína na primeira alimentação de jundiá (Rhamdia quelen) sob condições de laboratório. Foram testadas três rações balanceadas secas: ovo de peixe (TA), hidrolisado de carcaça do peixe (TB) e fígado de frango cru (TC), na quais foram analisadas, pelo crescimento, a biomassa final produzida e a sobrevivência das larvas. O ensaio teve uma duração de 20 dias, e as rações foram fornecidas ad libitum. As larvas alimentadas com ovo de peixe apresentaram os melhores resultados com peso médio individual de $340 \mathrm{mg}$, sobrevivência de $57 \%$ e biomassa final de $1.350 \mathrm{mg}$, diferindo significativamente dos demais tratamentos. Os resultados indicaram que a formulação de rações balanceadas com ovos de peixes fornecida na primeira alimentação de larvas de jundiá pode tornar-se uma alternativa promissora na larvicultura dessa espécie.

Palavras-chave: alimentação, larva, ovo de peixe, proteínas, rações artificiais, Rhamdia quelen.

\section{ABSTRACT}

This study aimed to evaluate different proteins sources in first feeding of jundiá (Rhamdia quelen) under laboratory conditions. Three balanced dry rations were tested, fish roe (TA), biological fish silage (TB) and crude chicken liver (TC) evaluating specific growth rate, final biomass produced and survival rate. The experiment was performed in 20 days, and all the rations were provided ad libitum. Larvae fed with fish roe presented better results, with $340 \mathrm{mg}$ of individual mean weight, 57\% of survival rate and $1.350 \mathrm{mg}$ of final biomass, differing significantly with the other treatments. The results show that the inclusion of fish roe in balanced rations offered at the first feeding of jundiá larvae may become a promising alternative for the hatchering of the species.
Key words: artificial diet, larvae, feeding, fish roe, protein, Rhamdia quelen.

\section{INTRODUÇÃO}

A produção de jundiá (Rhamdia quelen) em piscicultura é uma crescente atividade que deve ser baseada, entre outras coisas, na obtenção de larvas de boa qualidade. Embora tenha sido demonstrada a importância dos organismos vivos na alimentação das larvas de jundiá (LUCHINI \& SALAS, 1985), nos últimos anos, os pesquisadores utilizaram outras estratégias alimentares, tais como a co-alimentação (organismos vivos + alimentos artificiais) (BEHR et al., 2000; CARNEIRO et al., 2003; HERNÁNDEZ et al.,2006) e os alimentos exclusivamente artificiais (PIAIA et al., 1997; ULIANA et al., 2001; CARDOSO et al., 2004), os quais se mostraram mais vantajosos em relação ao alimento vivo, uma vez que sua produção é mais fácil e econômica (LAZO, 2000). Assim, diferentes fontes de proteína foram avaliadas para melhorar o desempenho em larvas de peixe. A utilização de fígado de aves cru na alimentação de larvas de jundiá demonstrou bons resultados no ganho de peso e na sobrevivência, em comparação com a farinha de hidrolisados de fígado ou peixe (CARDOSO et al., 2004).

Além disso, foi avaliada a incorporação de probióticos nas rações artificiais, seja como fonte de proteína (PIAIA \& RADÜNZ NETO, 1997), seja como

Instituto de Ictiología del Nordeste, Facultad de Ciencias Veterinarias, Universidad Nacional del Nordeste, (UNNE), Sargento Cabral 2139, Corrientes (Argentina). E-mail: dhernandez@vet.unne.edu.ar. *Autor para correspondência. 
promotora de maturação do sistema imunológico e digestivo, impedindo a colonização de patógenos e fornecendo moléculas de importância fisiológica (poliaminas) para o hospedeiro (TOVAR et al., 2000, 2002; GATESOUPE, 1999, 2007).

De acordo com os estudos descritos, não existe informação sobre a utilização de ovo de peixe como fonte nutricional na primeira alimentação de jundiá a fim de favorecer o crescimento das larvas nessa importante fase de desenvolvimento. $\mathrm{O}$ objetivo do trabalho foi, portanto, avaliar o efeito de diferentes rações na primeira alimentação do jundiá com adição de ovo de peixe.

\section{MATERIAL E MÉTODOS}

As larvas de jundiá foram obtidas por meio de reprodução induzida com hipófise de Prochilodus lineatus a partir de matrizes (peso corporal de 300 a $350 \mathrm{~g}$ ) do Instituto de Ictiología do Nordeste, em Corrientes, na Argentina, em outubro de 2006. Após a incubação, as larvas foram mantidas em caixas para acompanhar o desenvolvimento até quase completa absorção do conteúdo do saco vitelino e da abertura bucal (50h pós-eclosão). Posteriormente, foram distribuídas em lotes de 700 larvas (comprimento $=4,87 \mathrm{~mm}$ e peso $=0,7 \mathrm{mg}$ ), em nove aquários utilizados como unidades experimentais, contendo $23 \mathrm{~L}$ de água e aeração forçada, taxa de substituição da água de $0,4 \mathrm{~L} \mathrm{~min}{ }^{-1}$ durante 12 horas (ao dia) para a eliminação de resíduos. $\mathrm{O}$ experimento teve duração de 20 dias, e a temperatura da água foi registrada diariamente. Outros parâmetros de qualidade da água, tais como a condutividade $\left(\mu \mathrm{S} \mathrm{cm}^{-1}\right)$, o pH e o oxigênio dissolvido $\left(\mathrm{mg} \mathrm{L}^{-1}\right)$, foram registrados a cada 48 horas.

Foram avaliados três tratamentos alimentares: ração com $35 \%$ ovo de peixe (TA) (gônadas de fêmeas de Pseudoplatystoma corruscans em estado avançado de maturação, obtidas a partir de desperdícios do eviscerado gerados no porto de pesca comercial da cidade de Corrientes), 35\% hidrolisado de carcaça do peixe (TB) ou $35 \%$ de fígado de frango cru (TC). Cada ração continha também levedura de pão, lecitina de soja e premix vitamínico-minerais (Tabelas 1 e 2). Para obter proporções equilibradas nas rações, procedeuse à mistura dos ingredientes até a formação de uma pasta e posterior secagem na estufa $\left(38-40^{\circ} \mathrm{C}\right)$ por 48 horas. As rações foram moídas e peneiradas de acordo com a abertura da boca das larvas com granulometrias entre $100-200 \mu \mathrm{m}, 250-450 \mu \mathrm{m}$ e $600-800 \mu \mathrm{m}$ para a primeira, a segunda e a terceira semana, respectivamente. Todos os grupos de larvas foram
Tabela 1 - Composição das dietas utilizadas na primeira alimentação do jundiá (Rhamdia quelen) (totais $100 \mathrm{~g})$.

\begin{tabular}{llll}
\hline & & \multicolumn{3}{c}{-----Composição (\%)----- } \\
Ingrediente & A & B & C \\
& 35 & - & - \\
\hline Ovo de peixe & - & 35 & - \\
Hidrolisado de carcaça de peixe & - & - & 35 \\
Fígados de frango cru & 57 & 57 & 57 \\
Levedura de pão & 2 & 2 & 2 \\
Lecitina de soja $^{1}$ & 6 & 6 & 6 \\
Suplemento vitamínico e mineral $^{2}$ & 6 \\
\hline
\end{tabular}

${ }^{1}$ Adaptado de ULIANA et al., 2001

${ }^{2}$ Vitafac Super Acqua - Roche ${ }^{\circledR}$ (ingrediente/kg de dieta): vit. A 144.000UI; vit. D3: $28.800 \mathrm{UI}$; vit. E: $3.000 \mathrm{mg}$; vit. K3: $96 \mathrm{mg}$; vit. B1: $120 \mathrm{mg}$; vit. B2: 240mg; vit. B6: 90mg; vit. B12: 0,36mg; vit. B8: 12mg; vit. B5: 480mg; Ác. fólico: $72 \mathrm{mg}$; vit. B3: $1.800 \mathrm{mg}$; vit. C: $1.800 \mathrm{mg}$; Se: $360 \mathrm{mg}$; I: $20 \mathrm{mg}$; Cu: $60 \mathrm{mg}$; $\mathrm{Zn}$ : $840 \mathrm{mg}$; Mn: 600mg; Fe: $1.200 \mathrm{mg}$; Co: $24 \mathrm{mg}$.

alimentados diariamente às $8,11,14,17$ e 20h, durante todo o período experimental. As rações foram fornecidas ad libitum.

O crescimento foi avaliado aos 10,15 e 20 dias, estimando-se o peso de lotes de 30 larvas por aquário, usando uma balança de precisão de $0,1 \mathrm{mg}$, enquanto que as taxas de sobrevivência $(\% \mathrm{~S})$ e biomassa final (BF) foram estimadas a partir da contagem e pesagem total das larvas no final do período de experimentação.

O delineamento experimental foi inteiramente casualizado com três tratamentos e três repetições $(\mathrm{N}=9)$. O efeito dos tratamentos sobre o crescimento, a sobrevivência e a biomassa final foi avaliado pelo ANOVA, sendo os valores das médias comparados pelo

Tabela 2 - Composição proximal das dietas utilizadas na primeira alimentação do jundiá (Rhamdia quelen) (totais 100g).

\begin{tabular}{|c|c|c|c|}
\hline \multirow{3}{*}{ Composição proximal das dietas } & \multicolumn{3}{|c|}{------------(\%)----------- } \\
\hline & \multicolumn{3}{|c|}{-----Tratamentos------ } \\
\hline & A & $\mathrm{B}$ & $\mathrm{C}$ \\
\hline Umidade & 9,94 & 13,72 & 12,04 \\
\hline Proteína bruta & 53,70 & 50,75 & 53,48 \\
\hline Estrato etéreo & 7,80 & 7,74 & 8,15 \\
\hline Fibra bruta & 0,25 & 0,86 & 0,06 \\
\hline Estrato não nitrogenado & 21,14 & 20,24 & 19,00 \\
\hline Cinzas & 7,17 & 6,69 & 7,27 \\
\hline${ }^{1}$ Energia bruta Mcal kg ${ }^{-1}$ & 4,607 & 4,399 & 4,540 \\
\hline${ }^{1}$ BLAXTER, 1989. & & & \\
\hline
\end{tabular}


Teste de Tukey a 5\%. O crescimento foi avaliado a partir da taxa de crescimento específico $(\mathrm{TCE}=\%$ incremento do peso corporal por dia), que foi calculado a partir da seguinte equação:

$$
\mathrm{TCE}=\frac{100\left[\ln \left(\mathrm{P}_{2}\right)-\ln \left(\mathrm{P}_{1}\right)\right]}{\text { tempo }(\text { dias })}
$$

em que $\mathrm{P}_{1}$ y $\mathrm{P}_{2}$ representam o peso inicial e o final empresado em $\mathrm{mg}$ de um período determinado, respectivamente.

A análise foi realizada com o programa STATISTICA, versão 6.0 (Statsoft, 2001).

\section{RESULTADOS E DISCUSSÃO}

A qualidade da água foi semelhante nas diferentes unidades experimentais, com os seguintes valores médios: Temperatura $=25,9^{\circ} \mathrm{C} ; \mathrm{pH}=6,30 ;$ Oxigênio dissolvido $=6,53 \mathrm{mg} \mathrm{L}^{-1}$ e Condutividade $=91,2 \mu \mathrm{S} \mathrm{cm}^{-1}$, dentro dos parâmetros aceitáveis pela espécie (GOMES et al., 2000).

Os peixes alimentados com a ração formulada com ovo de peixe apresentaram TCE superiores aos demais grupos durante o período compreendido entre os 10 e 15 dias (Figura 1), resultando em pesos médios superiores no final do experimento (Figura 2, $\mathrm{P}<0,05$ ). $\mathrm{O}$ mesmo grupo de larvas também apresentou as taxas mais altas de sobrevivência (Figura 3, $\mathrm{P}<0,05$ ), resultando em maior produção de biomassa final (Figura 4, $\mathrm{P}<0,05$ ).

A utilização de ovos de diferentes espécies na alimentação humana e na alimentação animal tem sido de grande importância pelo seu valor nutritivo e pelo equilíbrio dos seus componentes. A gema do ovo cozido foi utilizada com sucesso nas rações balanceadas para a substituição de alimentos vivos na dieta de larvas de jundiá (LUCHINI \& CHAMBERS, 1985).

Estima-se que as necessidades nutricionais das larvas dos peixes sejam semelhantes à composição do vitelo de seu tipo, em que os principais componentes são proteínas e ácidos graxos poliinsaturados de cadeia longa. KANAZAWA et al. (1985) observaram que a fosfatidilcolina e a lecitina da farinha de soja e do ovo de peixe (bonito) foram igualmente eficazes no crescimento e na sobrevivência das larvas de Plecoglossus altivelis, mas, quando esses componentes foram obtidos de ovos de aves, não forneceram bons resultados.

O peso médio de $340 \mathrm{mg}$ estimado no presente trabalho para larvas alimentadas com ovos de peixes foi superior ao peso apresentado em outros estudos (PIAIA \& RADÜNZ NETO, 1997; ULIANA et al., 2001; CARDOSO et al., 2004), sugerindo que a utilização de ovo de peixe associada à levedura e lecitina de soja na formulação de rações balanceadas para larvas

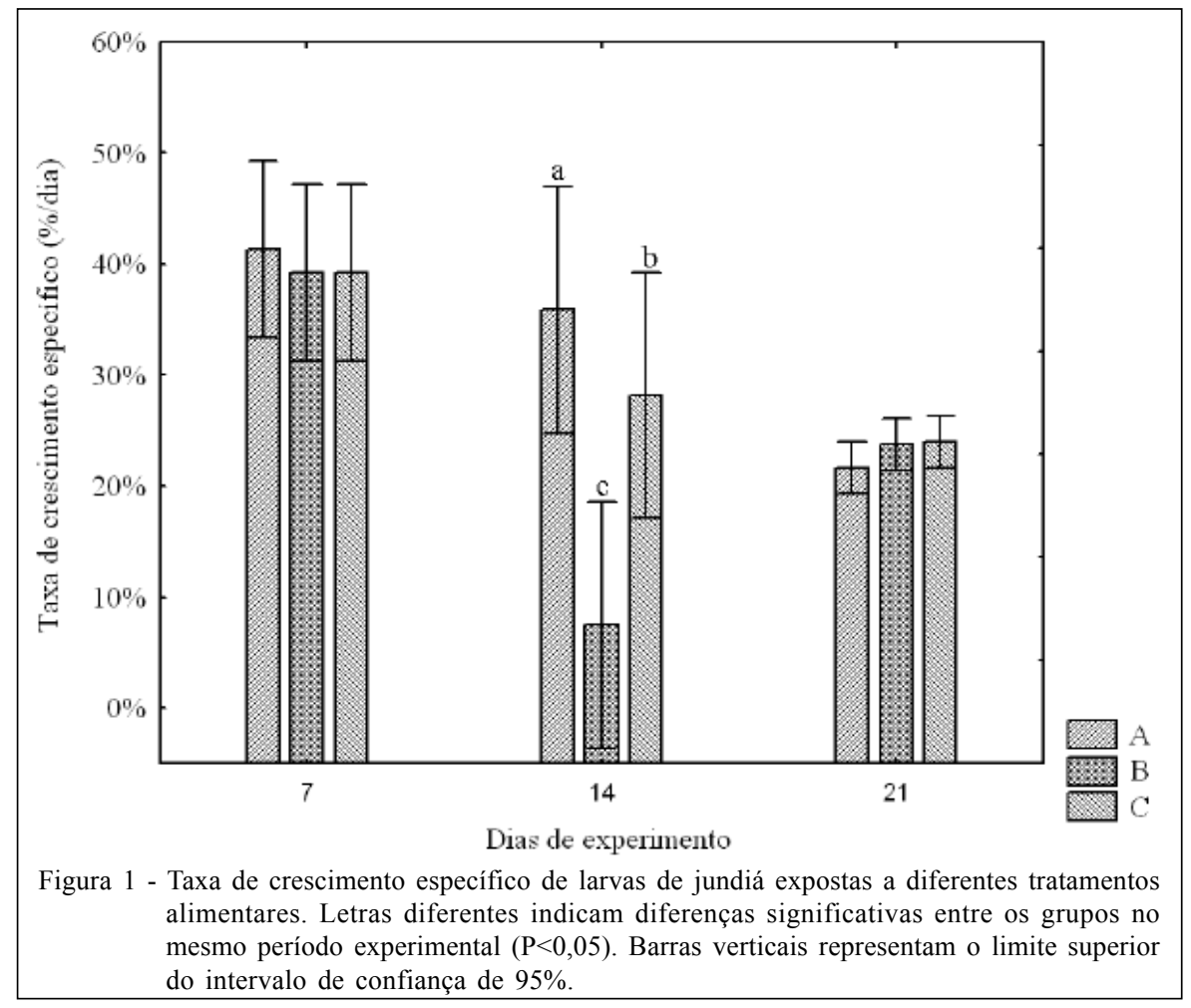

Ciência Rural, v.39, n.3, mai-jun, 2009. 


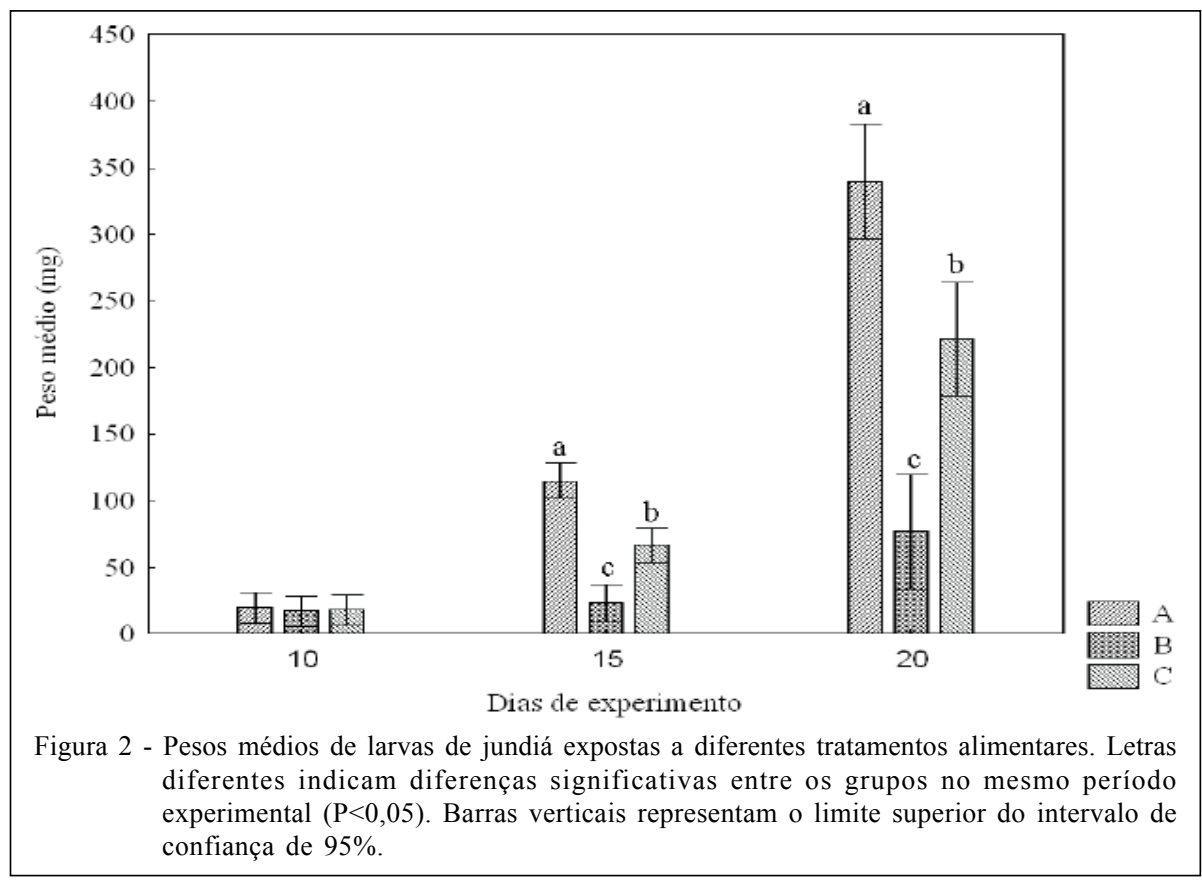

pode estimular mais o crescimento destas. Tal hipótese corrobora os resultados de SILVA et al. (2001), os quais demonstraram que a utilização de ovo de peixes na formulação de rações balanceadas melhorou o crescimento e a sobrevivência das larvas de Anguilla australis. No entanto, neste estudo, foram encontradas diferenças na composição proximal de aminoácidos e ácidos graxos, não somente entre os ovos das espécies testadas, mas também em relação ao período de maturidade do ovo.

Avaliando diferentes dietas na criação de larvas e juvenis de Sphoeroides annulatus, GARCÍA ORTEGA et al. (2002) observaram um aumento significativo do crescimento em juvenis alimentados com dietas frescas compostas com gônadas de atum e lulas. Assim, de acordo com os autores, este acontecimento poderia ser explicado pelo elevado teor de aminoácidos e pela boa palatabilidade.

Portanto, melhores pesos das larvas quando alimentadas com ovo de peixe, neste experimento, poderiam estar associados a um bom equilíbrio de aminoácidos e ácidos graxos essenciais fornecidos pelas gônadas de $\boldsymbol{P}$. corruscans, as quais se encontravam em fase avançada de maturação (perto da desova). Além disso, deve-se considerar que essa espécie posui uma relação filogenética próxima de jundiá, já que ambas as espécies podem apresentar necessidades nutricionais semelhantes durante os primeiros dias de vida.

Além disso, a contribuição de poliaminas ao sistema digestivo do peixe pela levedura pode ser de importância na etapa larval durante a maturação do sistema digestivo, melhorando a sobrevivência de jundiá. TOVAR et al. (2000, 2002), após analisarem diferentes linhagens de levedura como probiótico em larvas de Dicentrarchus labrax, constataram que, quando se empregou Debaryomyces hansenii HF1, a sobrevivência aumentou pouco mais de $8 \%$, evidenciando que as larvas tiveram rápida maturação do tubo digestivo, atribuindo o efeito observado à secreção de grandes quantidades de espermina e espermidina pelas leveduras.

Os efeitos de D. hansenii HF1 foram confirmados posteriormente quando incorporadas no regime alimentar de larvas de $\boldsymbol{D}$. labrax em quantidade definida como Unidades Formadoras de Colônia (UFC). Além disso, estas cresceram mais rapidamente, com evidente maduração pancreática e intestinal acelerada, melhorando a sobrevivência e o desenvolvimento (TOVAR-RAMÍREZ et al., 2004).

Após a inclusão de Saccharomyces cerevisae como probiótico na alimentação de larvas, juvenis e adultos de tilapia nilótica (Oreochromis niloticus) submetidas a estresse, LARA et al. (2002) mostraram que houve maior aumento na sobrevivência e no crescimento comparado com o uso de antibióticos como promotores de crescimento, confirmando que os probióticos som uma boa opção para substituir o uso de antibióticos.

Os pesos médios obtidos no TA foram superiores aos $122 \mathrm{mg}$ de pesos médios das larvas reportados por PIAIA \& RADÜNZ NETO (1997) para a

Ciência Rural, v.39, n.3, mai-jun, 2009. 


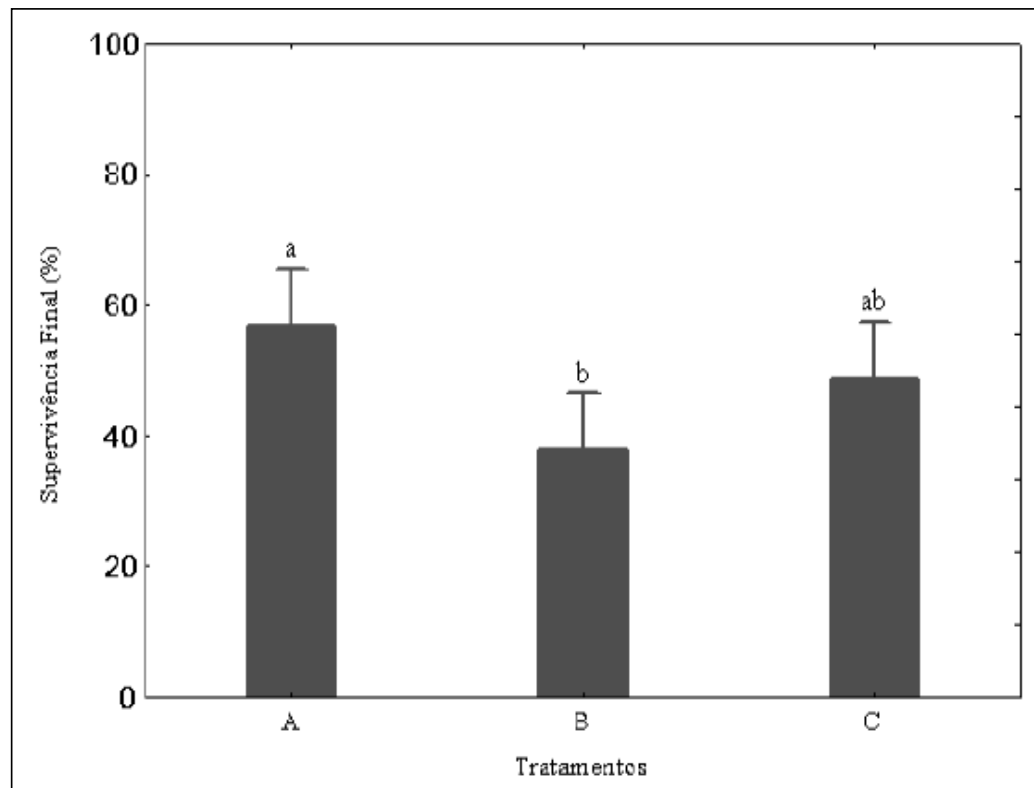

Figura 3 - Sobrevivência final (\%) das larvas de jundiá expostas a diferentes tratamentos alimentares. Letras diferentes indicam diferenças significativas entre os grupos no mesmo período experimental $(\mathrm{P}<0,05)$. Barras verticais representam o limite superior do intervalo de confiança de $95 \%$.

fórmula $50 \%$ levedura de cana e $30 \%$ fígado bovino com $41,44 \%$ de proteína bruta (PB) aos 21 dias; ainda, os autores encontram influência do nível de PB nos alimentos, estimando um aumento de $7,225 \mathrm{mg}$ para cada
$1 \%$ de proteína a mais na ração. Mais recentemente, ULIANA et al. (2001), utilizando a fórmula $57 \%$ levedura de cana e $30 \%$ fígado bovino, reportaram $184,89 \mathrm{mg}$ de pesos médios das larvas aos 21 dias.

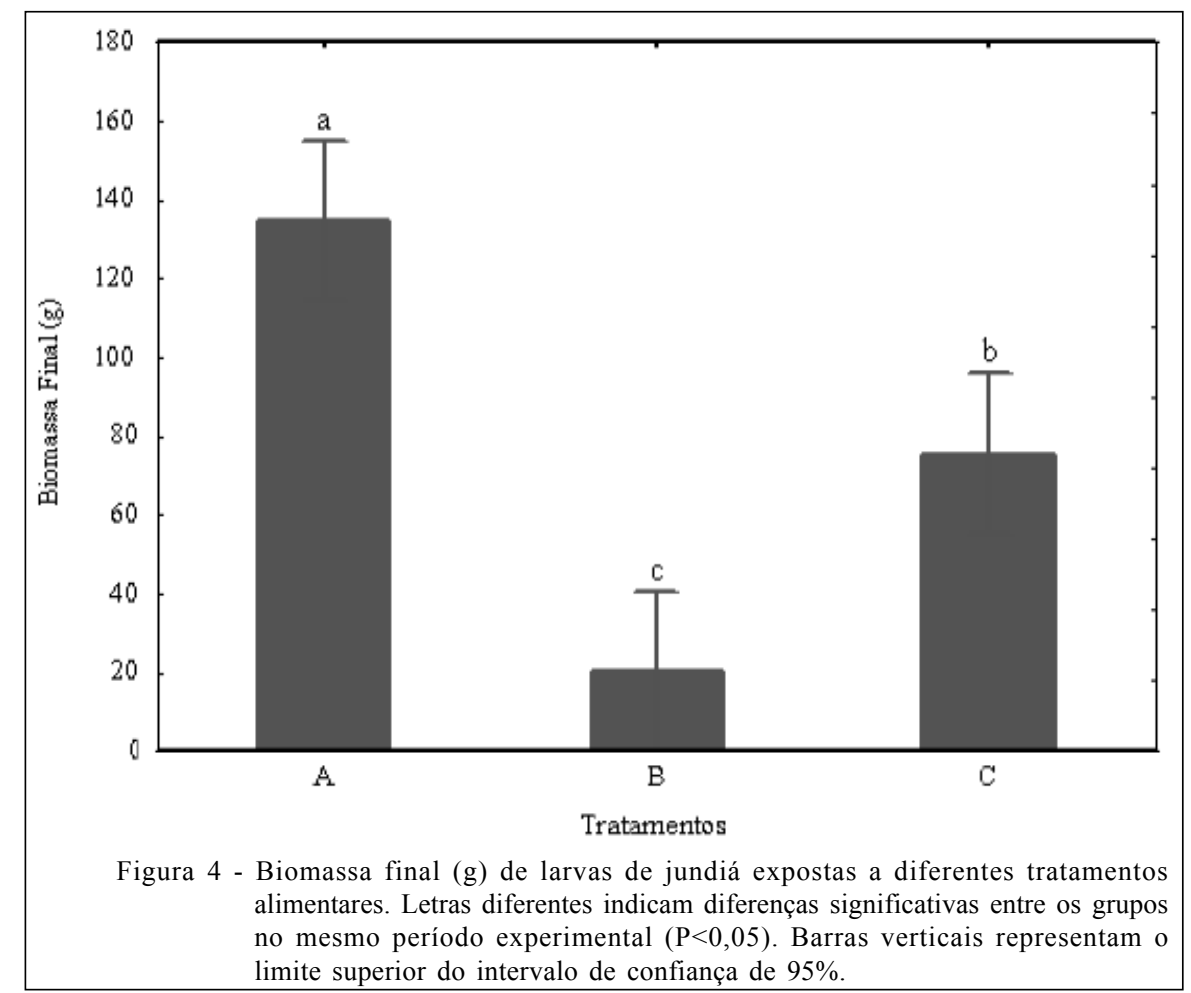

Ciência Rural, v.39, n.3, mai-jun, 2009. 
Resultados inferiores foram encontrados por CARDOSO et al. (2004), utilizando levedura de cana e fígado de aves na forma crua (em proporções semelhantes às utilizadas no TC do presente trabalho), com peso médio de 62,95mg em 21 dias de vida. Esses autores expressaram que as larvas de jundiá apresentaram grande variação na resposta a formulações similares de rações, influenciada possivelmente por fatores genéticos dos reprodutores e pelas diferentes épocas de desova.

Portanto, os valores de peso médio obtidos no presente trabalho, utilizando $35 \%$ de ovo de peixe de $\boldsymbol{P}$. corruscans na formulação de ração balanceada seca na primeira alimentação de larvas de jundiá, significaram aumentos de 2,77; 1,83 e 5,39 vezes, respectivamente, quando comparados aos três últimos trabalhos citados. Isso representa um ganho significativo para delinear estratégias no cultivo e no manejo de jundiá, garantindo a produção de larvas de boa qualidade.

\section{CONCLUSÕES}

Os resultados obtidos indicaram que a inclusão de ovo de peixe e levedura nas rações balanceadas fornecidas na primeira alimentação de larvas de jundiá pode ser uma alternativa para a larvicultura da espécie.

\section{AGRADECIMENTOS}

Os autores agradecem ao Doutor Alejandro Toro, pela ajuda fornecida na tradução do manuscrito, e ao financiamento pelo PICT 13.332 e pela SGCyT (UNNE) PI $001 / 2007$

\section{REFERÊNCIAS}

BEHR, E.R. et al. Ação do tempo e da forma de suplementação alimentar com Artemia franciscana sobre a sobrevivência e o crescimento de larvas de jundiá. Ciência Rural, v.30, n.3, p.503507, 2000. Disponível em: http://www.scielo.br/ scielo.php?script $=$ sci arttext \& pid $=$ S $0103-$ $84782000000300023 \& \operatorname{lng}=$ en\&nrm=iso\&tlng=pt. Doi: $10.1590 /$ S0103-84782000000300023.

BLAXTER, K. Energy metabolism in animals and man. In: HALVER, J.E.; HARDY, R.W. Fish nutrition. 3.ed. San Diego: Elsevier Science, 2002. Cap.1, p. 1-59.

CARDOSO, A.P. et al. Criação de larvas de jundiá (Rhamdia quelen) alimentadas com rações granuladas contendo fígados ou hidrolisados. Acta Scientiarum, v.26, n.4, p.457-462, 2004

CARNEIRO, P.C.F. et al. Live and formulated diet evaluation through initial growth and survival of jundiá larvae, Rhamdia quelen. Scientia Agricola, v.60, n.4, p.615-619, 2003.
DE SILVA, S.S. et al. Weaning of Australian shortfin glass eels (Anguilla australis): a comparison on the effectiveness of four types of fish roe. Aquaculture, v.195, p.133-148, 2001

GARCÍA-ORTEGA, A. et al. Advances in the nutrition and feeding of the bullseye puffer Sphoeroides annulatus. In: CRUZSUÁREZ, L.E. et al. (Eds.). Avances en nutrición acuícola VI. Memorias del VI Simposium Internacional de Nutrición Acuícola. México, 2002. p.187-196.

GATESOUPE, F.J. The use of probiotics in aquaculture. Aquaculture, v.180, p.147-165, 1999. Disponível em: http:/ / w w w. s c i e n c e d i r e c t . c o m / science? ob=ArticleURL\& udi=B6T4D-3X8G4YPD\&_user $=687358 \&$ rdoc $=1 \&$ fmt $=\&$ \&orig $=$ search $\&$ _sort $=\mathrm{d}$ $\& \mathrm{view}=\mathrm{c} \& \quad$ a c c t $=\mathrm{C} 000037899 \& \quad \mathrm{version}=$

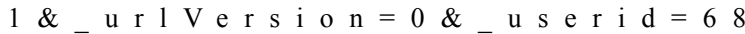
7358 \& md5=f0f041 a39ecfd5e9c524746185922261. Doi: $10.1016 / \mathrm{S} 0044-8486(99) 00187-8$.

GATESOUPE, F.J. Live yeasts in the gut: Natural occurrence, dietary introduction, and their effects on fish health and development. Aquaculture, v.267, p.20-30, 2007. Disponível em: http://www.sciencedirect.com/ science?_ob=ArticleURL\&_udi=B6T4D-4MV74Y9$1 \&$ _user $=687358 \&$ rdoc $=1 \&$ fmt $=\&$ \&_orig $=$ search $\& \quad$ s o r t $=$ d \& vi e $\bar{w}=\mathrm{c} \&$ a c c t $=$ C 000003789 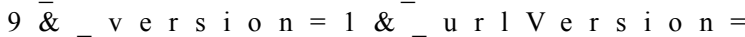 $0 \&$ userid $=687358 \& \mathrm{md} 5=9000 \mathrm{~b} 69 \mathrm{cafc} 5 \mathrm{cf} 56 \mathrm{a} 2 \mathrm{c} 192 \mathrm{c} 080 \mathrm{adfd} 30$. Doi: $10.1016 /$ j.aquaculture.2007.01.005

GOMES, L. et al. Biologia do jundiá Rhamdia quelen (Teleostei, Pimelodidae). Ciência Rural, v.30, n.1, p.179-185, 2000. Disponível em: http://www.scielo.br/scielo.php?script=sci_arttext\&pid=S0103$84782000000100029 \& \operatorname{lng}=$ en\&nrm=iso\&tlng=pt. Doi: $10.1590 /$ S0103-84782000000100029.

HERNÁNDEZ, D.R. et al. Evaluación de diferentes dietas en la primera alimentación del Bagre sudamericano (Rhamdia quelen). In: CUARTO CONGRESO IBEROAMERICANO VIRTUAL DE ACUICULTURA. Zaragoza, España. CIVA 2006. p.1151-1155.

KANAZAWA, A. et al. Effects of dietary bonito-egg phospholipids and some phospholipids on growth and survival of the larval ayu Plecoglossus altivelis. Zeitschrift Angewandte Ichthyologie, v.4, p.165-170, 1985.

LARA FLORES, M. et al. Avances en la utilización de probióticos como promotores de crecimiento en tilapia nilótica (Oreochromis niloticus). In: CRUZ-SUÁREZ, L.E. et al. (Eds.). Avances en nutrición acuícola VI. Memórias del VI Simposium Internacional de Nutrición Acuícola. Cancún, Quintana Roo, México, 2002. p.314-335.

LAZO, J. Conocimiento actual y nuevas perspectivas en el desarrollo de dietas para larvas de peces marinos. In: CRUZ SUÁREZ L.E. et al. (Eds.). Avances en nutrición acuícola V. Memorias del V Simposium Internacional de Nutrición Acuícola. Mérida, Yucatán, México, 2000. p.300-312.

LUCHINI, L.; SALAS, T. Primer alevinaje de bagre sudamericano, Rhamdia sapo (Val.) Eig. En condiciones controladas. Revista de la Asociación de Ciencias Naturales del Litoral, v.16, n.2, p.137-147, 1985. 
PIAIA, R. et al. Alimentação de larvas de jundiá (Rhamdia quelen), com dietas artificiais. Revista Ciência e Natura, v.19, p.119-131, 1997.

PIAIA, R.; RADÜNZ NETO, J. Efeito de níveis crescentes de levedura de álcool em rações contendo fígado bovino sobre a performance de larvas de jundiá (Rhamdia quelen). Ciência Rural, v.27, n.2, p.313-317, 1997.

STATISTICA (data analysis software system), version 6 . StatSoft, Inc. Tulsa, Oklahoma, USA, 2001.

TOVAR, D. et al. Effect of live yeast incorporation in compound diet on digestive enzyme activity in sea bass (Dicentrarchus labrax) larvae. Aquaculture, v.204, p.113123, 2002. Disponível em: http://www.sciencedirect.com/ science? ob=ArticleURL\& udi=B6T4D-44VVVR3B\&_user $=687358 \&$ \&doc $=1 \&_{-}$fmt $=\&$ \&orig $=$ search $\&$
_ s o r t $=$ d \& vi e w $=$ c \& _ a c c t $=$ C 0000037899 \& v e r s i o n $=1 \&$ \& r l V e r s i o n $=0$ \& userid $=687358 \& \mathrm{md} 5=193859666 \mathrm{~d} 958783 \mathrm{~d} 5 \mathrm{~d} 855970 \mathrm{bbd} 905 \mathrm{~b}$. Doi: $10.1016 / \mathrm{S} 0044-8486(01) 00650-0$.

TOVAR, D. et al. Efecto de la administración de levaduras en el proceso de maduración del tracto digestivo de peces. In: CRUZ -SUÁREZ, L.E. et al. (Eds.). Avances en nutrición acuícola. V memorias del V Simposium Internacional de Nutrición Acuícola. Mérida, Yucatán, México. 2000. p.33-46.

TOVAR-RAMÍREZ, D. et al. Influence of dietary live yeast on European sea bass (Dicentrarchus labrax) larval development. Aquaculture, v.234, p.415-427, 2004.

ULIANA, O. et al. Substituição parcial ou total de óleo de canola por lecitina de soja em rações para larvas de jundiá (Rhamdia quelen), pisces, Pimelodidae. Ciência Rural, v.31, n.4, p.677-681, 2001. 